\title{
Factors influencing the occurrence of the Endangered Baird's tapir Tapirus bairdii: potential flagship species for a Costa Rican biological corridor
}

\author{
Michael V. Cove, Lain E. Pardo Vargas, Juan Camilo de la Cruz \\ R. Manuel Sínola, Victoria L. Jackson, Joel C. Saénz and Olivier Chassot
}

\begin{abstract}
Baird's tapir Tapirus bairdii is categorized as Endangered on the IUCN Red List and is considered rare and locally extirpated from most of its historic range in Costa Rica. We conducted camera-trap and track surveys at 38 forested sites in and around the San Juan-La Selva Biological Corridor in the Northern Zone of Costa Rica. Cameras were set along established game trails and natural funnels and operated for 14-38 days per site. Additionally, we documented tapir tracks at many sites. We used survey photographs and track presence to create detection histories to estimate the habitat and survey-specific variables that influence the probability of detection and the probability of occurrence of Baird's tapir. The two major protected areas within and adjacent to the corridor were most positively associated with tapir occurrence, and forest cover and native and exotic tree plantations were also positively associated with tapirs' use of sites. Although the Baird's tapir is rare, our findings suggest that it is more resilient and better able to use available habitat in the fragmented corridor than previously thought. This is most likely a consequence of increased forest cover from reforestation and tree plantations and limited hunting pressure. Given its charismatic nature we recommend that Baird's tapir could be used as a flagship species for the San Juan-La Selva Biological Corridor, to raise local awareness about conservation and increase economic growth from ecotourism.
\end{abstract}

Keywords Baird's tapir, camera traps, Costa Rica, flagship species, occupancy model, probability of occurrence, San Juan-La Selva Biological Corridor, Tapirus bairdii

\footnotetext{
Michael V. Cove* (Corresponding author) and ViCTORIA L. JACKSON Department of Biology and Earth Science, University of Central Missouri, Warrensburg, Missouri 64093, USA. E-mail m.cove3@gmail.com

Lain E. Pardo Vargas, Juan Camilo de la Cruz, R. Manuel Spínola and Joel C. SAÉNZ Instituto Internacional en Conservación y Manejo de Vida Silvestre, Universidad Nacional, Heredia, Costa Rica

Olivier Chassot Centro Científico Tropical, San José, Costa Rica

*Current address: Department of Biology, North Carolina State University, Raleigh, North Carolina, 27695, USA

Received 27 June 2012. Revision requested 18 October 2012.

Accepted 9 January 2013. First published online 29 November 2013.
}

\section{Introduction}

With a geographical distribution restricted to Mesoamerica, Baird's tapir Tapirus bairdii is categorized as Endangered on the IUCN Red List of Threatened Species (Castellanos et al., 2008). The major threats to the species include habitat loss and fragmentation and local hunting (Koster, 2006; Castellanos et al., 2008). In Costa Rica the tapir is considered rare and locally extirpated from most of its historical range, occurring in remnant forest reserves and national parks (Wainwright, 2007). Although hunted extensively in the 1900 s for its meat and thick hide and because it damaged agricultural crops, the tapir is now protected in Costa Rica and there is little economic gain from killing this species (Wainwright, 2007).

Most studies of tapirs have been carried out in national parks and biological reserves, where the study area is often separated from rural communities and contains large tracts of protected primary forest (Foerster, 1998; Tobler, 2002). Licona et al. (2011) determined that the best predictor of lowland tapir Tapirus terrestris occurrence was travel time from the nearest city, serving as an index of a site's inaccessibility to people. Tobler (2002) found that in the Cordillera de Talamanca, southern Costa Rica, Baird's tapirs occurred in areas of dense vegetation and rarely used open habitats. However, Foerster (1998) determined that radiotagged tapirs in Corcovado National Park, Costa Rica, preferred secondary-growth forests where new shoots and small trees were readily available and easily consumed. Because of this preference Baird's tapir may be more likely to occur in disturbed and fragmented habitats than previously suggested.

The diet and feeding habits of Baird's tapirs have been described and synthesized (Naranjo, 2009) and differ from those of other tapir species (Fragoso, 1997). Baird's tapir has been observed to consume at least 98 species of plants, of which they eat the bark, leaves, fruit, shoots, vines and flowers (Naranjo, 2009). With such a generalist diet, food resources are probably not limiting tapir distribution in most Central American forests. Although fruits make up a large proportion of lowland tapir diet in the Amazon (Fragoso, 1997), fruit constitutes only $1.4-18.6 \%$ of the Baird's tapir diet (Naranjo, 2009). Despite the limited consumption of fruits and seeds, tapirs may still have a role in seed dispersal and thus reforestation (Fragoso, 1997). 


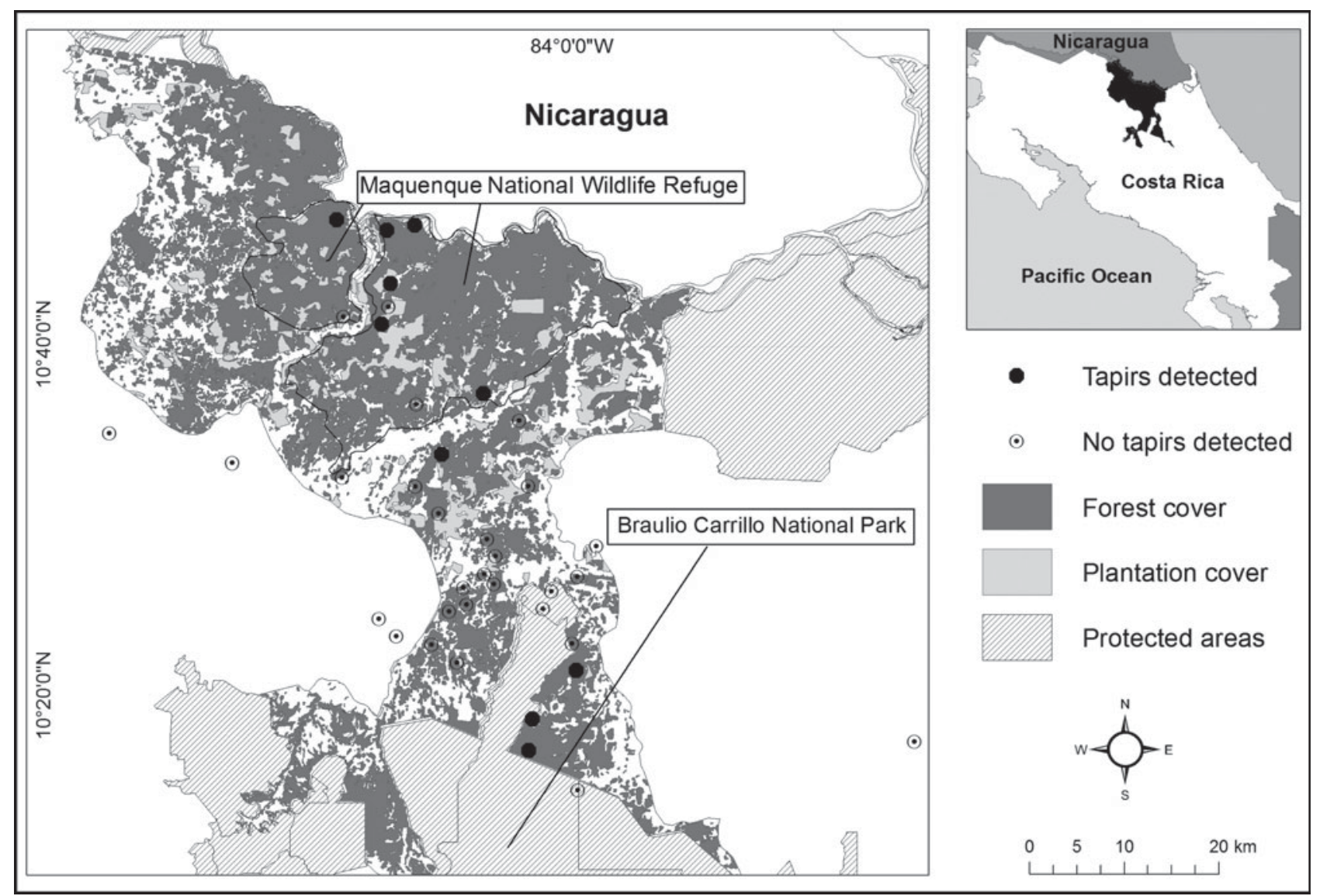

FIG. 1 Location of the study area in and around the San Juan-La Selva Biological Corridor, showing protected areas, forest cover, tree plantation cover, camera-trap and track survey locations, and sites where Baird's tapir Tapirus bairdii was detected. The inset shows the location of the main map in Costa Rica.

In a previous study in the San Juan-La Selva Biological Corridor, Chassot et al. (2006) used geographical information system technologies to conduct a habitat viability analysis for Baird's tapir in northern Costa Rica to estimate habitat availability and categorize priority areas for the species' persistence. They estimated that $22 \%$ of the corridor contained habitat with high or medium potential for tapir occurrence, with the remaining $78 \%$ classified as low potential habitat and excluded zones. The objective of our study was to use camera traps and track surveys to document tapir presence within and adjacent to the biological corridor and integrate these data into an occupancy analysis (MacKenzie et al., 2006) to estimate the habitat and survey-specific variables that influence the probability of detection $(p)$ and the probability of occurrence $(\psi)$ of Baird's tapir.

\section{Study area}

The San Juan-La Selva Biological Corridor (Fig. 1) is the northernmost portion of the Mesoamerican Biological Corridor in Costa Rica. This $2,425 \mathrm{~km}^{2}$ corridor links the expansive Indio Maíz Biological Reserve of south-eastern
Nicaragua and the lowland rainforest ecosystems of northern Costa Rica to the Braulio Carrillo National Park and other montane forests in central Costa Rica (Chassot et al., 2006).

Although deforestation of primary forest occurs within the corridor and surrounding area, government incentives (Forestry Law no. 7575) have encouraged reforestation and plantations of native and exotic trees, which have maintained much forest cover (Morse et al., 2009; Chassot et al., 2010). The majority of the land within the corridor is private and, although many villages and private groups have established reserves and lodges for small-scale agriculture and farming, large-scale agricultural plantations and cattle operations are prevalent in the corridor and the surrounding landscape. As of 2005 the corridor also includes the Maquenque Mixed-Use National Wildlife Refuge $\left(597 \mathrm{~km}^{2}\right)$, which is the corridor's highest priority conservation unit because of its high forest connectivity. Maquenque is largely privately owned and has fewer restrictions and protections than national parks (Chassot et al., 2006). Focusing our study on the corridor allowed us to assess the factors influencing tapir occurrence in human-altered landscapes, which will be important priority areas as human 
populations expand and encroach on pristine forest habitats in the Neotropics.

\section{Methods}

We conducted a survey of medium- and large-sized mammals within the corridor and surrounding area to investigate tapir occurrence and habitat suitability within this fragmented landscape. Site selection for the camera survey was largely based on accessibility ( $<5 \mathrm{~km}$ from access point), landowner permission and forest size $(>75 \mathrm{ha})$, but also on representativeness of the corridor landscape. We also surveyed isolated forest patches outside the corridor. We allocated a large portion of our survey effort to sites in the south of the corridor because they are the most fragmented and potentially the most important for maintaining connectivity to Braulio Carillo National Park (Chassot et al., 2010). All forest sites were located on private land and consisted of eco-lodge forest reserves, tree plantations, cattle ranches or agricultural plantations. As the estimated home range of Baird's tapir is $0.62-2.32 \mathrm{~km}^{2}$ (Foerster, 1998) we selected survey sites at least $2 \mathrm{~km}$ apart to ensure independence among forest sites. However, because tapirs are large-bodied and are capable of travelling long distances between sites (Fragoso, 1997), we considered $\psi$ to represent site use as opposed to occurrence (MacKenzie et al., 2006).

From June 2009 to July 2011 we surveyed a total of 38 forest sites in and adjacent to the San Juan-La Selva Biological Corridor. To avoid the pitfalls of using a single camera trap to make inferences about a forest patch (Efford \& Dawson, 2012) we used 4, 6 or 8 camera stations spaced $>250 \mathrm{~m}$ apart in a relative grid at each site. We use the term grid loosely because, although we systematically placed traps within an array, camera locations focused efforts on wildlife game trails. Although other camera-trap studies have set cameras along trails and roads (Tobler et al., 2008) we avoided areas of high human use because of the high risk of theft of the equipment. The use of a variable number of cameras, inevitable malfunctions, and some theft led to varying numbers of camera-trap nights per site, which was accounted for in our analysis. We used remotely triggered infrared cameras (Scout Guard SG550, HCO Outdoor Products, Norcross, USA) or remotely triggered traditional flash cameras (Stealth Cam Sniper Pro Camera 57983, Stealth Cam LLC, Grand Prairie, USA). Cameras operated at each site for 14-38 days and were checked weekly or as often as was logistically possible.

At 17 sites we used a global positioning system to record the cumulative distance covered while hiking into forest interior from the access point and between cameras, and documented observed tapir tracks. Tapir tracks are large and easily observed in muddy substrate but some sites were not surveyed for tracks because of unsuitable substrate, or at the discretion of the observer if vegetation was too dense or the cumulative distance travelled was $<2 \mathrm{~km}$. Although there are modelling techniques that can estimate detection probabilities for linear transects where detections may not be independent (Hines et al., 2010), we surveyed an insufficient number of sites to estimate such parameters. Additionally, tracks did not fade away between visits so multiple track surveys were not independent. For these reasons we recorded all tracks at a site as a single detection and incorporated this single detection into the subsequent occupancy models.

To measure habitat variables we used ArcGIS v. 10.0 (ESRI, Redlands, USA) to create a land-use/land-cover map of the corridor and surrounding area. We created a $1 \mathrm{~km}$ radius buffer around a central point at each site to measure variables at a landscape scale. We selected habitat covariates based on the known ecology of tapirs and factors that could plausibly affect their occurrence and detectability (Wainwright, 2007; Padilla et al., 2010; Licona et al., 2011).

We measured the linear distance $(\mathrm{km})$ to the nearest village as an index of human presence and/or disturbance. We also measured forest cover as the percentage of the site buffer covered by primary or secondary forest. On the basis of apparent tapir use (M. Cove, pers. obs.) we measured the buffer percentage of tree plantations as a separate covariate, which included native and exotic species such as teak Tectona grandis, roble coral Terminalia amazonia and melina Gmelina arborea. Because access to water should positively affect the occurrence of tapirs we measured the linear distance $(\mathrm{m})$ to the closest river or water body. However, we removed this covariate from the analysis because rivers and water bodies are abundant in the corridor and the mean distance to water was $<500 \mathrm{~m}$, which is an insignificant distance for a tapir to travel. Any land that was used for agricultural purposes or cattle ranching was accounted for in the land-use/land-cover models because the remaining land percentages from site buffers that were not forested were in these categories. We used a binary covariate to denote sites within a $5 \mathrm{~km}$ buffer zone adjacent to the boundaries of the two major protected areas in the region: Braulio Carrillo National Park and Maquenque National Wildlife Refuge. We used a categorical value for this covariate because several sites were within and connected to each of the protected areas, so a continuous covariate appeared to be an inappropriate measure. The final covariates that we measured were the total number of different cover-type patches and the cumulative length of all roads within each site buffer, which are indices of habitat heterogeneity and habitat fragmentation. Survey-specific covariates were the number of camera-trap nights (number of cameras $\times$ number of functioning nights) per site and the method (camera trap vs track detection) used to determine the difference between camera traps and track surveys. We standardized all continuous covariates to $z$ scores for analysis but performed no other transformations. 
TABLE 1 Hypotheses of a priori detection $(p)$ models for Baird's tapir Tapirus bairdii, with the model structure and expected result, based on data from camera-trap and track surveys in the San Juan-La Selva Biological Corridor (Fig. 1) during $2009-2011$.

\begin{tabular}{|c|c|c|c|}
\hline Hypothesis & Model & Model structure & Expected result \\
\hline No habitat covariates affect detection & $p()$. & $\beta_{0}$ & \\
\hline $\begin{array}{l}\text { Tracks are more effective than cameras } \\
\text { for detecting tapirs }\end{array}$ & $p$ (track) & $\beta_{0}+\beta_{1}($ track $)$ & $\beta_{1}>0$ \\
\hline $\begin{array}{l}\text { Increasing the number of camera-trap nights } \\
\text { has a positive effect on detection }\end{array}$ & $p$ (trpnts) & $\beta_{0}+\beta_{1}$ (trpnts) & $\beta_{1}>0$ \\
\hline $\begin{array}{l}\text { Increasing forest cover has a negative effect on } \\
\text { detection because activities are less concentrated }\end{array}$ & $p$ (for) & $\beta_{0}+\beta_{1}$ (for) & $\beta_{1}<0$ \\
\hline $\begin{array}{l}\text { Tapir activity is concentrated away from human } \\
\text { disturbance, which increases detection }\end{array}$ & $p$ (dist) & $\beta_{0}+\beta_{1}($ dist $)$ & $\beta_{1}>0$ \\
\hline $\begin{array}{l}\text { Habitat heterogeneity has a positive effect } \\
\text { on detection }\end{array}$ & $p$ (het) & $\beta_{0}+\beta_{1}$ (het) & $\beta_{1}>0$ \\
\hline $\begin{array}{l}\text { Method, total camera-trap nights, forest cover, } \\
\text { distance to village, \& habitat heterogeneity all } \\
\text { affect detection }\end{array}$ & $p$ (global) & $\begin{array}{l}\beta_{0}+\beta_{1}(\text { track })+\beta_{2}(\text { cam })+\beta_{3}(\text { trpnts }) \\
+\beta_{4}(\text { for })+\beta_{5}(\text { dist })+\beta_{6}(\text { het })\end{array}$ & $\begin{array}{l}\beta_{1}>0, \beta_{2}>0, \beta_{3}>0, \beta_{4}<0, \\
\beta_{5}>0, \beta_{6}>0\end{array}$ \\
\hline
\end{tabular}

After the surveys were complete we combined all photos and partitioned each site detection history into 5-day blocks for a maximum total of seven repeat surveys, including the single track-sign detection survey. We defined camera detections as independent if they were at intervals $>_{1}$ hour. We fitted these detection histories and site/survey covariates into a single-season occupancy model implemented in PRESENCE 2.4 (Hines, 2009). Although the data were collected over several field seasons we did not resample any sites in a multi-season framework, and because this analysis refers to $\psi$ as site use we do not believe that the grouping of the field seasons violates any of the assumptions of the modelling process. We used seven a priori models (Table 1), including a constant (null) and global set, to estimate the influence of habitat covariates and survey methods on detection probabilities in a detection model. The global model was only used to estimate overdispersion (explained below) and to ensure that the saturated model converged and there was no covariate interaction. We then used the covariates that contained high model support and had strong effects on detection as a constant covariate set in the subsequent tapir occurrence models. For the occurrence models we developed 13 a priori hypotheses (Table 2).

The best approximating models were evaluated based on the Akaike Information Criterion corrected for small sample size $\left(\mathrm{AIC}_{\mathrm{c}}\right)$ and Akaike weights $\left(\omega_{i}\right)$. To evaluate model fit we performed 10,000 simulated parametric bootstraps for the global model (all covariates) and estimated an overdispersion factor $(\hat{c})$. For models that had $\hat{c}>_{1}$ we inflated the standard errors by a factor of $\sqrt{ } \hat{c}$ and used a quasi-corrected $\mathrm{AIC}_{\mathrm{c}}\left(\mathrm{QAIC}_{\mathrm{c}}\right)$, which penalizes the model with an additional parameter (i.e. $K+1$ ) for model selection (Burnham \& Anderson, 2002). We consider all models contained within the $95 \%$ CI (confidence interval) ( $\left.\sum \omega_{i}>0.95\right)$ to have substantial support as the top-ranking models and consider covariate effects significant if 95\% confidence intervals exclude zero.

All animal research was in accordance with the guidelines established by The American Society of Mammalogists (Sikes et al., 2011). The camera-trapping protocol was approved by the University of Central Missouri Institutional Animal Care and Use Committee (IACUC, Permit No. 10-3202).

\section{Results}

From a total effort of 6,288 camera-trap nights we obtained 12 independent photos of tapirs at seven sites and detected tapir tracks at three additional sites. Of the 10 sites with tapir detections, six were within the Maquenque National Wildlife Refuge. If we assume perfect detection the naive occupancy estimate is $26 \%$ at the surveyed sites.

From the parametric bootstraps the global detection model suggested slight overdispersion ( $\hat{c}=1.23$ ), so all detection model standard errors were inflated by $\sqrt{ } \hat{c}$ and models were evaluated using $\mathrm{QAIC}_{\mathrm{c}}$. The global detection model contained the most support $\left(\omega_{i}=0.389\right.$; Table 3$)$, with forest cover $\left(\beta_{1}=-1.01 \pm 0.40 \mathrm{SE}\right)$ and total number of trap-nights $\left(\beta_{3}=-0.04 \pm 0.01 \mathrm{SE}\right)$ both presenting as significant negative influences on detection. The number of camera-trap nights was also present in the second-ranking model as a negative covariate; however, with the low value of the slope, we consider this to be an artefact in our data and do not consider this covariate to have any significance. Though we consider the negative influence of forest cover to be valid, the forest cover model with no other covariates ranked lower than the constant model. The method model with variable detection by tracks vs cameras is not included in the ranking because it failed to converge. The distance from village covariate agreed with the a priori hypothesis of a positive influence but was not significant. Habitat 
TABLE 2 Hypotheses of a priori occurrence $(\psi)$ models for Baird's tapir, with the model structure and expected result, based on data from camera-trap and track surveys in the San Juan La Selva Biological Corridor (Fig. 1) during 2009-2011.

\begin{tabular}{|c|c|c|c|}
\hline Hypothesis & Model & Model structure & Expected result \\
\hline No habitat covariate effect & $\psi()$. & $\beta_{0}$ & \\
\hline $\begin{array}{l}\text { Positive effect within and adjacent to } \\
\text { protected areas }\end{array}$ & $\psi($ prot $)$ & $\beta_{0}+\beta_{1}($ prot $)$ & $\beta_{1}>0$ \\
\hline $\begin{array}{l}\text { Positive effect as distance to village } \\
\text { increases }\end{array}$ & $\psi($ dist $)$ & $\beta_{0}+\beta_{1}($ dist $)$ & $\beta_{1}>0$ \\
\hline $\begin{array}{l}\text { Negative effect as habitat heterogeneity } \\
\text { increases }\end{array}$ & $\psi($ het $)$ & $\beta_{0}+\beta_{1}$ (het) & $\beta_{1}<0$ \\
\hline $\begin{array}{l}\text { Negative effect as number of roads within } \\
\text { site buffers increases }\end{array}$ & $\psi($ road $)$ & $\beta_{0}+\beta_{1}(\mathrm{road})$ & $\beta_{1}<0$ \\
\hline Positive effect as forest cover increases & $\psi($ for $)$ & $\beta_{0}+\beta_{1}($ for $)$ & $\beta_{1}>0$ \\
\hline $\begin{array}{l}\text { Positive effect as tree plantation cover } \\
\text { increases }\end{array}$ & $\psi($ plant $)$ & $\beta_{0}+\beta_{1}($ plant $)$ & $\beta_{1}>0$ \\
\hline $\begin{array}{l}\text { Positive effect as forest cover increases } \\
\text { \& positive effect as plantation cover } \\
\text { increases }\end{array}$ & $\psi($ for + plant $)$ & $\beta_{0}+\beta_{1}($ for $)+\beta_{2}($ plant $)$ & $\beta_{1}>0, \beta_{2}>0$ \\
\hline $\begin{array}{l}\text { Positive effect with protected status } \\
\& \text { increasing distance from village }\end{array}$ & $\psi($ prot + dist $)$ & $\beta_{0}+\beta_{1}($ prot $)+\beta_{2}($ dist $)$ & $\beta_{1}>0, \beta_{2}>0$ \\
\hline $\begin{array}{l}\text { Positive effect with increasing distance } \\
\text { from village \& negative effect as habitat } \\
\text { heterogeneity increases }\end{array}$ & $\psi($ dist + het $)$ & $\beta_{0}+\beta_{1}($ dist $)+\beta_{2}($ het $)$ & $\beta_{1}>0, \beta_{2}<0$ \\
\hline $\begin{array}{l}\text { Negative effect as habitat heterogeneity } \\
\& \text { number of roads within site buffers } \\
\text { increase }\end{array}$ & $\psi($ het + road $)$ & $\beta_{0}+\beta_{1}($ het $)+\beta_{2}($ road $)$ & $\beta_{1}<0, \beta_{2}<0$ \\
\hline $\begin{array}{l}\text { Positive effect with protection, and as } \\
\text { forest cover \& plantation cover increase }\end{array}$ & $\psi($ prot + for + plant $)$ & $\beta_{0}+\beta_{1}($ prot $)+\beta_{2}($ for $)+\beta_{3}($ plant $)$ & $\beta_{1}>0, \beta_{2}>0, \beta_{3}>0$ \\
\hline $\begin{array}{l}\text { Protection status, forest cover, plantation } \\
\text { cover, distance to village, roads } \\
\text { \& habitat heterogeneity all affect } \\
\text { occurrence }\end{array}$ & $\psi($ global $)$ & $\begin{array}{l}\beta_{0}+\beta_{1}(\text { prot })+\beta_{2}(\text { for }) \\
\quad+\beta_{3}(\text { plant })+\beta_{4}(\text { dist })+\beta_{5}(\text { road }) \\
\quad+\beta_{6}(\text { het })\end{array}$ & $\begin{array}{c}\beta_{1}>0, \beta_{2}>0, \beta_{3}>0 \\
\beta_{4}>0, \beta_{5}<0, \beta_{6}<0\end{array}$ \\
\hline
\end{tabular}

heterogeneity, however, disagreed with the a priori hypothesis and presented a negative but insignificant effect. Because no covariate had significant support and effect, and given our relatively limited data set, we determined it most appropriate to evaluate occurrence models using a constant (null) detection set.

The global occurrence model suggested no overdispersion, so models were evaluated based on $\mathrm{AIC}_{\mathrm{c}}$ values. The protected area covariate was contained in the top three competing models and had the highest model support $\left(\sum \omega_{i}=0.953\right)$, with a very strong positive influence on occurrence (Table 4$)$. Distance to village was also a positive factor $\left(\beta_{2}=1.78 \pm\right.$ SE 1.37) in the top-ranking model but had a confidence interval that strongly overlapped zero. Forest cover and native and exotic tree plantation cover were both within the $95 \%$ confidence set and agreed with a priori hypotheses with positive influences on tapir occurrence. When modelled together without other covariates, forest cover $\left(\beta_{1}=1.62 \pm\right.$ SE 0.79$)$ and plantation cover $\left(\beta_{2}=1.11 \pm\right.$ SE 0.55$)$ both had significant and strong positive effects on tapir occurrence. Habitat heterogeneity and road covariates had no model support and did not affect tapir occurrence.

\section{Discussion}

This study provides the first camera-trap photographic evidence of Baird's tapirs occurring in the San Juan-La Selva Biological Corridor. Although we set cameras along game trails and areas of high tapir use, tapirs were not commonly detected by cameras when present. Tapir tracks were detected at all sites for which photographs were obtained as well as at sites where no tapirs were photographed, which corresponds with the findings of Licona et al. (2011). The limited detections with either method suggest that the species, although present, may still be rare in the corridor.

Sites within and adjacent to the Maquenque National Wildlife Refuge and Braulio Carrillo National Park had a strong positive relationship with tapir occurrence. This suggests that these two state-protected areas are vital for the survival of tapirs in the Northern Zone. It is important to consider that all of our sites were $>75$ ha; sites significantly smaller, even when adjacent to the protected areas, may not be large enough to support tapirs unless directly connected through reforestation. The high habitat suitability of the Maquenque region is a result of the area having the least fragmented forest cover and the least human presence 
TABLE 3 Model selection statistics for all models (except $\mathrm{p}$ (track), which did not converge) of detection probability ( $p$ ) for Baird's tapir, with untransformed coefficients of habitat and sampling covariates, based on data from camera-trap and track surveys in the San Juan-La Selva Biological Corridor (Fig. 1) during 2009-2011.

\begin{tabular}{|c|c|c|c|c|c|c|c|c|}
\hline \multirow[b]{2}{*}{ Model } & \multirow[b]{2}{*}{$\Delta_{i}^{2}$} & \multirow[b]{2}{*}{$\omega_{i}{ }^{3}$} & \multirow[b]{2}{*}{$K^{4}$} & \multicolumn{5}{|c|}{ Untransformed coefficients of covariates $(\mathrm{SE})^{1}$} \\
\hline & & & & Intercept & Forest & Distance & Trap-nights & Heterogeneity \\
\hline$p()$. & 2.08 & 0.116 & 2 & $-0.96(0.38)$ & & & & \\
\hline$p$ (trpnts) & 0.36 & 0.274 & 3 & $1.56(0.62)$ & & & $-0.02(0.00)$ & \\
\hline$p$ (for) & 4.06 & 0.043 & 3 & $-0.82(0.40)$ & $-0.29(0.37)$ & & & \\
\hline$p$ (dist) & 1.48 & 0.156 & 3 & $-1.41(0.51)$ & & $0.46(0.27)$ & & \\
\hline$p$ (het) & 2.75 & 0.083 & 3 & $-1.34(0.47)$ & & & & $-0.58(0.39)$ \\
\hline$p($ global $)$ & 0.00 & 0.328 & 6 & $-3.32(1.07)$ & $-1.01(0.40)$ & $0.57(0.34)$ & $-0.04(0.01)$ & $-0.28(0.64)$ \\
\hline
\end{tabular}

TABLE 4 Model selection statistics for the 95\% confidence set and global occurrence model with untransformed coefficients of habitat covariates on the probability of occurrence ( $\psi$-site use) of Baird's tapir, based on data from camera-trap and track surveys in the San Juan-La Selva Biological Corridor (Fig. 1) during 2009-2011

\begin{tabular}{|c|c|c|c|c|c|c|c|c|}
\hline \multirow[b]{2}{*}{ Model } & \multirow[b]{2}{*}{$\Delta_{i}^{2}$} & \multirow[b]{2}{*}{$\omega_{i}{ }^{3}$} & \multirow[b]{2}{*}{$K^{4}$} & \multicolumn{5}{|c|}{ Untransformed coefficients of covariates $(\mathrm{SE})^{1}$} \\
\hline & & & & Intercept & Protected & Distance & Forest & Plantation \\
\hline$\psi($ prot $)$ & 2.98 & 0.156 & 3 & $-26.44(2.47)$ & $26.43(2.47)$ & & & \\
\hline$\psi($ for + plant $)$ & 7.24 & 0.019 & 4 & $-1.23(0.63)$ & & & $1.62(0.79)$ & $1.11(0.55)$ \\
\hline$\psi($ prot + dist $)$ & 0.00 & 0.693 & 4 & $-28.12(3.33)$ & $28.15(3.33)$ & $1.78(1.37)$ & & \\
\hline$\psi($ prot + for + plant $)$ & 4.11 & 0.089 & 5 & $-37.83(2.45)$ & $37.26(2.45)$ & & $1.27(0.83)$ & $0.92(0.60)$ \\
\hline$\psi($ global $)$ & 7.62 & 0.015 & 8 & $-28.09(4.15)$ & $27.21(4.15)$ & $1.93(1.54)$ & $2.29(1.77)$ & $1.23(0.77)$ \\
\hline
\end{tabular}

${ }^{1}$ Coefficients are in logit space and relate to standardized or categorical covariate values (prot $=$ within or directly adjacent to protected area, dist $=$ distance to nearest village, for $=$ forest cover, plant $=$ tree plantation $)$ and detection $(p)$ was modelled as constant. Values in bold indicate that confidence intervals exclude zero.

${ }^{2} \Delta_{i}, \mathrm{AIC}_{\mathrm{c}}$ difference

${ }^{3} \omega_{i}$, Akaike weight

${ }^{4} K$, number of model parameters

within the corridor (Chassot et al., 2006, 2010). Additionally, a study of change in land-use and landcover (Chassot et al., 2010) showed that the loss of habitat was significantly lower than outside the biological corridor. Occurrence may also be influenced by the Refuge's proximity to Nicaragua. The Refuge forms the border on the San Juan River and connects with the Indio Maíz Biological Reserve across the river. Tapirs are hunted by indigenous people in Nicaragua (Koster, 2006) and the Reserve is one of the largest strongholds for the species in that country. The natural barrier of a river has little or no effect on tapir dispersal and it is likely that the Indio Maíz Biological Reserve hosts a source population for the Northern Zone of Costa Rica. This further supports the suggested importance of the forest in this region and warrants its inclusion as a priority conservation unit within the corridor (Chassot \& Monge, 2002). Similarly, distance from the closest village was supported by the top model as an index of human accessibility and human disturbance influencing tapir occurrence. The positive association of tapirs at sites with increasing distance from villages may be a result of higher abundance and concentration of tapir activities in these less disturbed areas. This corresponds with the results of Tobler (2002), which suggested that tapirs in southern Costa Rica were more abundant in areas with limited human presence.

The model of forest cover and plantation cover included primary and secondary rainforest and tree plantations, all of which provide cover and food resources for tapirs. Because the model included these three types of tree cover, the majority of the sites were within habitats that were classified as low to medium potential habitat in previous landscape analysis (Chassot et al., 2006). Our findings suggest that tapir occurrence is positively related to forest and plantation cover and that tapirs benefit directly from secondary forest regeneration and native and exotic tree plantations stimulated by government incentives. Tapirs may also be more resilient and adapted to living in recovering forests than previously suggested, and this 
corresponds with results for radio-tracked tapirs that preferred secondary forest in Corcovado National Park (Foerster, 1998). Other tapir species are important seed dispersers (Fragoso, 1997) and the occurrence of Baird's tapirs in secondary forests and tree plantations could make them important community members in reforestation in the region. Further evidence of the resilience of Baird's tapir in the region is the lack of effects of road and habitat heterogeneity covariates on their occurrence. The majority of roads in the Northern Zone are unpaved but as human presence and urbanization increases roads may have stronger effects on population fragmentation.

Although hunting and illegal poaching occur in the corridor, tapirs are not targeted and, as far as we are aware from speaking with local people, they are generally left alone (O. Chassot, pers. obs.). This is different from other regions within the species' geographical distribution. In many areas the species is hunted extensively, even unsustainably, for meat, and has led to its extirpation in some cases (Koster, 2006). Pacas Cuniculus paca, peccaries Tayassu pecari and Pecari tajacu, and deer Odocoileus virginianus and Mazama americana are the most commonly targeted prey by hunters in the corridor (M. Cove, pers. obs.; Wainwright, 2007), hence their presence may free the tapir from hunting and poaching pressure. Nevertheless, the proponents of the Maquenque National Wildlife Refuge suggest that economic gains from alternative ecotourism (Chassot \& Monge, 2002) and many years of environmental education, combined with a shift from hunting towards more sustainable activities and enforced forestry regulations, have contributed to a general decline in hunting. Tapirs are also spared from hunting and poaching because they cause only limited damage to agricultural crops in the area. However, with future agricultural expansion, human-tapir conflict could become more common.

Tapirs are potentially an excellent flagship conservation species for the region, given their Endangered status and charismatic nature (Walpole \& Leader-Williams, 2002), but also their apparent resilience and the respect with which they are held by local people. The great green macaw Ara ambigua has already served as a flagship species for the region (Chassot \& Monge, 2002) but large mammals have proved to be more effective for this purpose than birds and smaller mammals (Walpole \& Leader-Williams, 2002). Tigers Panthera tigris, elephants Elephas maximus and rhinos Rhinoceros unicornis have all stimulated tourismdriven economies and increased public awareness of conservation in Asia (Walpole \& Leader-Williams, 2002). The jaguar Panthera onca could serve this purpose in Costa Rica but the elusive cat is not highly revered by the local people because of cattle depredation. The tapir, however, causes only limited agricultural damage and would be an excellent alternative. As a flagship species the tapir would play a socio-economic role in helping protect the lowland rainforest ecosystem through increased awareness, both locally and internationally, and visitation by foreign tourists (Walpole \& Leader-Williams, 2002). The establishment of Baird's tapir as another flagship species for the San JuanLa Selva Biological Corridor and the Maquenque National Wildlife Refuge would increase public and local awareness of conservation issues and could stimulate the economy through ecotourism and forest regeneration incentives and hence help support local economies and forest conservation in the region.

Although our findings suggest that this rare species still warrants concern, the San Juan-La Selva Biological Corridor may be able to support more tapirs than previously estimated. This highlights the importance of the corridor and continuing reforestation in maintaining a network of connectivity for tapir dispersal from Nicaragua to the central range of Costa Rica. With increased awareness and economic gains, it would also be in the best interest of the local people to value the Maquenque National Wildlife Refuge. This may ease social-economic tensions within the corridor and allow monitoring of the species and additional biodiversity conservation research to continue in the lowland rainforest ecosystems of Costa Rica.

\section{Acknowledgements}

We thank all the field assistants and lodges that helped with logistics for this research. Special thanks to Daniel Corrales, Roberto Salom, and Javier Carazo of PantheraCosta Rica, Finca Pangola, Laguna del Lagarto Lodge, Maquenque Lodge, Selva Verde Lodge and Holbrook Travel for their assistance and continued support. Funding for this research was provided by Universidad Nacional de Costa Rica and the University of Central Missouri International Center. Research was also supported and permitted by the National System of Conservation Areas-Ministry of the Environment, Energy and Telecommunication.

\section{References}

Burnham, K.P. \& Anderson, D.R. (2002) Model Selection and Multimodel Inference: A Practical Information-Theoretic Approach, 2nd edition. Springer-Verlag, New York, USA.

Castellanos, A., Foerester, C., Lizcano, D.J., Naranjo, E., Cruz-Aldan, E., Lira-Torres, I. et al. (2008) Tapirus bairdii. In IUCN Red List of Threatened Species v. 2010.4. Http://www. iucnredlist.org [accessed 12 November 2012].

Chassot, O. \& Monge, G. (2002) Great green macaw: flagship species of Costa Rica. PsittaScene, 53, 6-7.

Chassot, O., Monge, G. \& Jiménez, V. (2006) Evaluación del hábitat para la danta Centroamericana (Tapirus bairdii) en la zona norte de Costa Rica. Tapir Conservation, 15, 17-23.

Chassot, O., Chaves, H., Finegan, B. \& Monge, G. (2010)

Dinámica de paisaje en la Zona Norte de Costa Rica: implicaciones 
para la conservación del bosque tropical muy húmedo. Ambientales, 39, 37-53.

EFFord, M.G. \& DAwson, D.K. (2012) Occupancy in continuous habitat. Ecosphere, 3, 32.

Foerster, C. (1998) Ecología de la danta Centroamericana Tapirus bairdii en un bosque húmedo tropical de Costa Rica. MSc thesis. Universidad Nacional, Heredia, Costa Rica.

Fragoso, J.M.V. (1997) Tapir-generated seed shadows: scale-dependent patchiness in the Amazon rain forest. Journal of Ecology, 85, 519-529.

Hines, J.E. (2009) PRESENCE 2.4-Software to Estimate Patch Occupancy and Related Parameters: USGS-PWRC. Http:// www.mbr-pwrc.usgs.gov/software/presence.html [accessed 10 April 2009].

Hines, J.E., Nichols, J.D., Royle, J.A., MacKenzie, D.I., Gopalaswamy, A.M., Samba Kumar, N. \& Karanth, K.U. (2010) Tigers on trails: occupancy modelling for cluster sampling. Ecological Applications, 20, 1456-1466.

Koster, J.M. (2006) Assessing the sustainability of Baird's tapir hunting in the Bosawas Reserve, Nicaragua. Tapir Conservation, 15, 23-28.

Licona, M., McCleery, R., Collier, B., Brighsmith, D.J. \& Lopez, R. (2011) Using ungulate occurrence to evaluate community-based conservation within a biosphere reserve model. Animal Conservation, 14, 206-214.

MacKenzie, D.I., Nichols, J.D., Royle, J.A., Pollock, K.H., Bailey, L.L. \& Hines, J.E. (2006) Occupancy Estimation and Modeling. Academic Press, Burlington, USA.

Morse, W.C., Schedlbauer, J.L., Sensie, S.E., Finegan, B., Harvey, C.A., Hollenhorst, S.J. et al. (2009) Consequences of environmental service payments for forest retention and recruitment in a Costa Rican biological corridor. Ecology and Society, 14, 23.
NARAnjo, E.J. (2009) Ecology and conservation of Baird's tapir in Mexico. Tropical Conservation Science, 2, 140-158.

Padilla, M., Dowler, R.C. \& Downer, C.G. (2010) Tapirus pinchaque (Perissodactyla: Tapiridae). Mammalian Species, 42, 166-182.

Sikes, R.S., Gannon, W.L. \& The Animal Care and Use Committee of The American Society of Mammalogists (2011) Guidelines of the American Society of Mammalogists for the use of wild animals in research. Journal of Mammalogy, 92, 235-253.

Tobler, M.W. (2002) Habitat use and diet of Baird's tapirs (Tapirus bairdii) in a montane cloud forest of the Cordillera de Talamanca, Costa Rica. Biotropica, 34, 468-474.

Tobler, M.W., Carrillo-Percastegui, S.E., Leite Pitman, R., Mares, R. \& Powell, G. (2008) An evaluation of camera traps for inventorying large- and medium-sized terrestrial rainforest mammals. Animal Conservation, 11, 169-178.

Wainwright, M. (2007) The Mammals of Costa Rica: A Natural History and Field Guide. Cornell University Press, Ithaca, USA.

Walpole, M.J. \& Leader-Williams, N. (2002) Tourism and flagship species in conservation. Biodiversity and Conservation, $11,543-547$.

\section{Biographical sketches}

Michael Cove uses non-invasive sampling techniques to study mammal community ecology, both locally and internationally. JUAN Camilo de la Cruz and Lain Pardo study Neotropical mammal assemblages. Manual Sínola and Joel Saénz conduct research on landscape changes and community dynamics of various taxa in the Neotropics. VICTORIA JA CKSON researches the spatial ecology of mammals. Olivier Chassot studies landscape changes within the San Juan-La Selva Biological Corridor and community dynamics of various taxa. 